

\title{
Sonia Andrade e Letícia Parente, duas videoartistas brasileiras em uma exposição de arte feminista de vanguarda dos anos $1970^{*}$
}

\author{
Sonia Andrade and Letícia Parente, two Brazilian video artists in a 1970s \\ feminist avant-garde art exhibition
}

\author{
Ms.Ana Claudia Camila Veiga de França** \\ Dr.Ronaldo de Oliveira Corrêa ${ }^{* * *}$
}

\begin{abstract}
Resumo
Neste artigo, analisamos a presença de obras de Letícia Parente (1930-1991) e Sonia Andrade (1935) na exposição La Vanguardia Feminista de los años 70. Obras de la Verbund Collection, Vienna, sediada no Centro de Cultura Contemporânea de Barcelona, entre 2019 e 2020. Para tanto, estabelecemos como objetivo identificar intencionalidades no projeto curatorial, a partir da análise dos vídeos Preparação $1 \mathrm{e}$ Tarefa 1, de Letícia Parente, e do vídeo sem título de Sonia Andrade, percorrendo também algumas das produções que compartilham o espaço expográfico com as obras das artistas brasileiras. Por procedimento metodológico, recorremos a investigações sobre videoarte brasileira; à análise de fotografias e diários de campo produzidos durante visitas à exposição e ao catálogo Sammlung Verbund: The Verbund Art Collection, Vienna, sobre a coleção de arte feminista a partir da qual a exposição foi elaborada. Por resultados, explicitamos contradições e potencialidades que atravessam a participação de Letícia Parente e Sonia Andrade na exposição La Vanguardia Feminista de los años 70.
\end{abstract}

\section{Palavras-chave}

Artistas mulheres. Arte feminista. Exposições de arte feminista. Videoarte brasileira. Vanguarda dos anos 1970.

\begin{abstract}
In this paper, we investigate the presence of artworks by Letícia Parente (1930-1991) and Sonia Andrade (1935-) in the exhibition La Vanguardia Feminista de los años 70. Obras de la Verbund Collection, Vienna, held at the Center for Contemporary Culture in Barcelona (CCCB), between 2019 and 2020. For this purpose, we set as a goal identifying intentionalities in the curatorial project, based on the analysis of the videos Preparação 1 and Tarefa 1, by Letícia Parente, and the untitled video by Sonia Andrade, also covering some of the artworks that shared the expographic space with the Brazilian artists. As methodological procedure, we resort to investigations on Brazilian video art; photographs and field diaries produced during visits to the exhibition and to the Sammlung Verbund Catalog, which presents the collection of feminist art from which the exhibition was created. For results, we describe contradictions and potentialities that cross the participation of Letícia Parente and Sonia Andrade in the exhibition La Vanguardia Feminista de los años 70.
\end{abstract}

\section{Keywords}

Women artists. Feminist art. Feminist art exhibitions. Brazilian video art. Vanguard of the 1970s. 


\section{Duas videoartistas brasileiras em uma coleção de vanguarda feminista}

No terceiro andar do Centro de Cultura Contemporânea de Barcelona (CCCB), Letícia desenha uma boca nos lábios cobertos por um esparadrapo. Em um monitor não muito distante, Sônia contorna a cabeça com um cordão, pressionando os fios sobre a pele até deformar o rosto. Essas são imagens de obras em vídeo de duas artistas brasileiras, Letícia Parente (1930, Salvador - 1991, Rio de Janeiro) ${ }^{1} \mathrm{e}$ Sonia Andrade (1935, Rio de Janeiro). A exposição no CCCB parte da coleção de arte feminista de vanguarda intitulada Sammlung Verbund: The Verbund Art Collection, Vienna. Junto com Regina Vater (1943, Rio de Janeiro), Sônia e Letícia são as três brasileiras dentre 67 artistas da coleção que foram incluídas na exposição La Vanguardia Feminista de los años 70 do CCCB². Ainda foram acrescentadas à edição barcelonesa obras de oito artistas locais ${ }^{3}$. Letícia e Sonia têm expostas obras em vídeo, nas quais as próprias artistas encenam ações que mais adiante descreveremos.

Gabriele Schor ${ }^{4}$, diretora e fundadora da Sammlung Verbund: The Verbund Art Collection, Vienna ${ }^{5}$, define como vanguarda feminista a produção de artistas que nos anos 1970 trabalharam questionando construções sociais sobre mulheres (Schor, 2015). A coleção se estabeleceu em 2004 e já foi exposta em países como Itália, Bélgica, Suécia, Alemanha, Inglaterra, Noruega e República Tcheca. Sammlung Verbund: The Verbund Art Collection, Vienna é constituída por fotografias, vídeos, pinturas, colagens e artefatos, com mais de 1000 obras de 142 artistas (Sammlung Verbund, 2020). 0 catálogo da coleção consultado na biblioteca do CCCB é uma edição de 2015 e abrange apenas uma parte do conjunto, com 600 trabalhos de 48 artistas. A organização do catálogo é de Gabriele Schor, com a colaboração de diversas autoras e autores, em capítulos temáticos e sessões dedicadas a algumas das artistas e suas obras. Na publicação também está expressa a intenção ambiciosa do conjunto, qual seja: "ampliar o escopo da história da arte e realinhar suas coordenadas", com ênfase na conexão entre os termos "feminismo" e "vanguarda" (Schor, 2015).

No CCCB, Feminismes! (em catalão) - ou jFeminismos! (em espanhol) - , tem na curadoria Grabriele Schor e Marta Segarra ${ }^{6}$ e é o nome do conjunto de duas exposições: La Vanguardia Feminista de los años 70. Obras de la Verbund Collection, Vienna e Coreografías de Género (CCCB, 2019). Uma exposição desemboca na outra e é possível começar o percurso por qualquer uma delas. Coreografías de Género é composta, sobretudo, por produções recentes que incorporam a pluralidade das discussões de gênero contemporâneas. No painel de apresentação se destaca a impossibilidade de separar debates atuais sobre sexismo de outras formas de dominação, como o racismo, a homofobia, a transfobia, 0 especismo ${ }^{7}$ e 0 desprezo por pessoas mais pobres, imigrantes e deficientes.

Entre as duas exposições há também uma linha do tempo que contextualiza as principais conquistas do movimento feminista na Catalunha entre as décadas de 1970 e 20108. No mesmo espaço, há um apanhado sobre quadrinhos feministas intitulado Cómic y feminismo: El cuerpo como conflicto, com documentos originais e um mural com reproduções de quadrinistas precursoras e contemporâneas, com a curadoria de Marika Vila ${ }^{9}$ (CCCB, 2019).

Embora Cómic y feminismo: El cuerpo como conflicto e Coreografías de Género façam parte do contexto expográfico investigado, neste ensaio é a exposição na qual estão as obras videográficas de Letícia e Sonia que mais nos interessa, La Vanguardia Feminista de los años 70. Esta é composta por 5 seções temáticas: Dona-de-casa, mãe, esposa; Reclusão e evasão; Os ditames da beleza; A sexualidade feminina e Jogos de encenação ${ }^{10}$. As seções estão organizadas em sequência, mas compõem uma geografia expográfica que pode ser percorrida de muitas maneiras, com mais de 200 obras (CCCB, 2019) ${ }^{11}$, ou seja, apenas uma parte do acervo. 
Além de um conjunto numeroso de obras e artistas, associada à ¡Feminismos!, foi elaborada uma série de atividades: uma playlist de filmes ${ }^{12}$ disponíveis para assistir nas salas de projeção do Arxiu Xcèntric, 0 arquivo de cinema experimental do CCCB; uma série de visitas comentadas ${ }^{13}$ e um ciclo de conferências, debates e apresentações ${ }^{14}$. Assim, o recorte que aqui propomos para discutir as obras de Letícia e Sonia, expostas em La Vanguardia Feminista de los años 70, implica pensar partes de um mosaico amplo e heterogêneo.

Nos próximos itens, partindo dos vídeos de Letícia e Sonia, detalhamos as seções nas quais esses estão localizados e descrevemos algumas das obras vizinhas, mapeando as intencionalidades do projeto curatorial de La Vanguardia Feminista de los años 70. Em diálogo com outras leituras sobre videoarte brasileira, descrevemos também algumas pessoas, instituições, eventos e condições materiais que nos anos 1970 fizeram parte do contexto de realização das obras de Letícia e Sonia. São elementos que permitem reconhecer circuitos artísticos dos quais as artistas fizeram parte e que eventualmente sugerem outras leituras às suas obras. Contrastar diferentes perspectivas sobre as obras e as artistas possibilita, assim, indicar algumas das contradições e potencialidades implicadas na participação de ambas na exposição apresentada em Barcelona. Por fim, entendemos que Preparação I e Tarefa I de Letícia e a obra sem título de Sonia são fragmentos importantes não apenas para ¡Feminismos! e para a coleção Sammlung Verbund: The Verbund Art Collection, mas também para a produção de videoarte brasileira dos anos 1970.
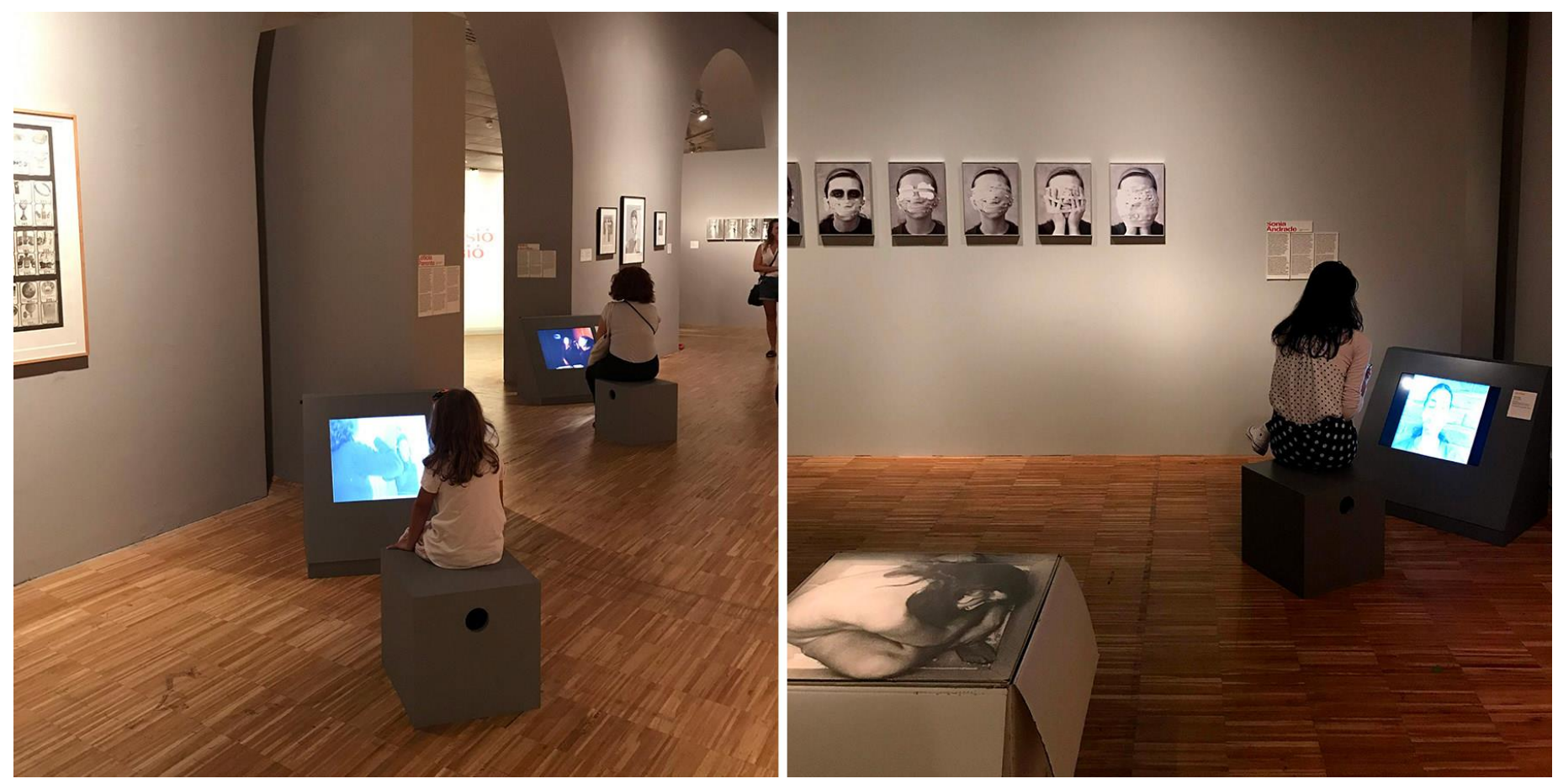

Figs.1-2. À esquerda, fotografia da estrutura para exibição de Preparação 1 (1975) e Tarefa 1 (1982), de Letícia Parente, e Outro dia na vida de uma dona-de-casa (1977), de Mako Idemitsu, na seção Dona-de-casa, mãe, esposa. À direita, estrutura para a exibição do vídeo sem título (1974-1977), de Sonia Andrade, na seção Reclusão e Evasão. Fotografias de Ana Claudia França. 


\section{Letícia Parente e outros tensionamentos domésticos na seção Dona-de-casa, mãe, esposa}

Na seção Dona-de-casa, mãe, esposa [fig. 1], o trabalho de Letícia é o terceiro audiovisual exposto ${ }^{15}$. No CCCB, cada vídeo da exposição está apresentado em uma estrutura de madeira acomodada no chão, com uma tela inclinada para cima e um banco à frente, convidando a sentar. As legendas nas paredes comunicam em catalão, espanhol e inglês algumas informações, destacando momentos da trajetória de trabalho da artista, do contexto de produção da obra e, eventualmente, interpretações e relações com obras vizinhas. Preparação I (1975) $)^{16}$ e Tarefa I (1982) ${ }^{17}$ são exibidos em sequência pelo mesmo monitor. Em alguns momentos, riscos horizontais atravessam a tela e as cores parecem esverdear, características próprias de imagens produzidas na década de 1970 em Portapack (a primeira câmera portátil produzida pela marca Sony) e Betamax colorido (um formato doméstico de gravação, também da marca Sony).

As condições materiais para que artistas como Letícia e Sonia pudessem realizar seus trabalhos em vídeo nas décadas de 1970 e 1980 eram mínimas, segundo Arlindo Machado (2007) e Cacilda Teixeira da Costa (2007). Os equipamentos para captura e projeção de imagens eram onerosos e raros e nem sempre foi possível a elaboração de cópias ou a guarda adequada dos materiais. De modo geral, a edição posterior à captura era inviável, portanto "editava-se diretamente na câmera durante a gravação ou com lâmina de barbear e fita adesiva posteriormente, ou ainda, concebia-se o trabalho num único plano contínuo, tomando em tempo real, para que não houvesse a necessidade de edição" (Machado, 2007: 22). Foi também pela dificuldade de fazer cópias dos trabalhos que alguns vídeos de Letícia se perderam. Isso porque era comum enviar a única ou a principal versão da obra para festivais, o que em alguns casos resultava no extravio do material. Marca Registrada (1980), por exemplo, "foi dado como perdido, em uma mostra na Argentina, no CAIC ${ }^{18}$, tendo retornado anos depois" (Parente, 2011: 29).

Mas Preparação 1 sobreviveu às intempéries da preservação videográfica dos anos 1970 e chegou em 2019 a Barcelona. No vídeo, vemos Letícia se penteando pelo reflexo de um espelho de banheiro. A artista corta um pedaço de esparadrapo e o cola na boca, para em seguida desenhar na fita adesiva 0 contorno e o preenchimento dos lábios com um batom. 0 mesmo gesto se repete nos olhos. Ao final, passa as mãos pelo cabelo e pelo rosto, como se estivesse finalizando um ritual. Para Mirtes Marins de Oliveira (2005), a obliteração dos olhos e da boca em Preparação 1 faz referência à autocensura do olhar e da expressão em um momento de extrema violência para o Brasil: a ditadura civil-militar que perdurou no país entre 1964 e 1985.

Os créditos iniciais de Preparação 1 indicam Jom Azulay como responsável pela captura das imagens, atividade também referida como VT (videotape). Jom Tob Azulay ${ }^{19}$, produtor e diretor audiovisual, era quem possuía um aparelho Portapack da marca Sony, preto e branco, $1 / 2$ polegada, trazido dos Estados Unidos. No Rio de Janeiro, Azulay filmou trabalhos de artistas como Anna Bella Geiger, Sonia Andrade, Ivens Olinto Machado, Ângelo de Aquino e Fernando Cocchiarale20 (Machado, 2007). Em 1975, na ocasião da primeira participação brasileira em um evento internacional dedicado ao vídeo, apenas artistas cariocas ${ }^{21}$ conseguiram se inscrever, pois puderam contar com 0 aparelho que Jom havia colocado à disposição (Ibidem; COSTA, 2007). Tratava-se de uma mostra de videoarte no Institute of Contemporary Art da Universidade da Pensilvânia, na cidade estadunidense de Filadélfia, com curadoria de Suzanne Delehanty22. Na opinião de Cacilda Costa (2007: 70), este evento foi o episódio decisivo que impulsionou "a organização de um grupo de artistas no Rio e induziu à formação do Setor de Vídeo no MAC/USP".

Cacilda Costa, curadora e crítica de arte, assim como Azulay, fez parte da rede de pessoas que propiciou produções e exibições de trabalhos de artistas nos primórdios da videoarte brasileira, segundo 
a própria Cacilda explica em artigo para a coletânea organizada por Arlindo Machado, Made in Brasil. Três décadas do vídeo brasileiro. Walter Zanini23 foi o responsável por comprar um equipamento para o Museu de Arte Contemporânea da Universidade de São Paulo (MAC USP), onde criou um setor de vídeo em $1977^{24}$ que existiria até a sua saída da instituição em 1978 (Costa, 2007). Uma mostra inaugural ocorreu em maio de 1977 e, dentre as/os sete artistas participantes ${ }^{25}$, estavam Letícia e Sonia (Ibidem). Foi também nesse espaço que aconteceu a primeira mostra solo de artista, com a projeção de uma série de oito vídeos de Sonia, da qual faz parte o seu vídeo sem título exibido no CCCB.

De Tarefa 1, Cacilda Costa foi produtora, informação que consta nos créditos iniciais, escritos à mão em folhas de papel em branco, o que confere um certo ar de improviso à obra. Letícia, de macacão e sandálias brancas, deita em uma tábua de passar roupa, onde se acomoda com a barriga para baixo. Em seguida, entra em cena uma mulher negra, de vestido preto, empunhando um ferro de passar que usa não só para passar a roupa, mas também Letícia. Não é possivel ver o rosto de nenhuma das duas. A câmera se move pouco, acompanhando apenas o movimento das mãos negras que esticam o tecido e manejam o ferro de passar. Tanto na legenda da obra quanto no catálogo da coleção é destacada a reflexão racial suscitada por Tarefa I. Schor (2015) avalia que a obra evidencia as diferenças de classe e raça entre as duas mulheres, não obstante, ambas estarem subordinadas ao sistema patriarcal.

De ambos os vídeos projetados de Letícia nada é possivel escutar, embora a legenda indique que exista sonorização. É que os sons que ecoam por toda a sala são de Semiótica da cozinha (1975)26, de Martha Rosler (1943, Nova York, EUA). Em Dona-de-casa, mãe, esposa, segundo o totem explicativo, o destaque é para a segunda onda feminista, tematizando os papéis limitantes aos quais as mulheres estiveram sujeitas, evidenciando a dimensão política da vida doméstica, com abordagens que muitas vezes fizeram uso de ironia e bom-humor.

Em Semiótica da Cozinha é a própria Martha que apresenta em ordem alfabética acessórios de cozinha, pronunciando seus nomes em voz alta. A artista os manipula de modo brusco e instrucional, fazendo uma referência crítica e irônica aos programas de culinária. Eventualmente, Martha bate um artefato no outro, produzindo barulhos metalizados e estridentes que compõem uma trilha sonora ambiente não apenas para os vídeos de Letícia, mas para toda a seção. Além de Semiótica da Cozinha, destacamos mais quatro obras vizinhas à Tarefa 1 e Preparação 1 [fig. 3], das artistas Mako Idemitsu, Karin Mack, Renate Eisenegger e Birgit Jürgenssen [fig. 4].

No vídeo Outro dia de uma dona-de-casa (1977)27, Mako Idemitsu (1940, Tóquio, Japão) incorpora uma mulher em várias situações cotidianas, desde o despertar até o anoitecer, em espaços públicos e privados, sempre vigiada por uma televisão presente em cena, sintonizada na imagem de um olho que ocupa a tela inteira, onipresente e vigilante. A legenda da exposição conta que Mako, cineasta e videoartista, comprou sua primeira câmera Super8 com a intenção de extrapolar os papéis de mãe e esposa, uma questão que a motivou a produzir Outro dia na vida de uma dona-de-casa.

Sala de passar roupa (1975)28, de Karin Mack (1940, Viena, Áustria), é um conjunto de quatro fotografias em que Karin passa roupa em uma tábua de passar [fig. 4]. No último retrato, é a própria artista que acaba estirada na tábua, usando um vestido preto e uma renda cobrindo o rosto. Para Schor (2005: 37), Karin interpretou 0 ato de passar roupa como "uma prática contemplativa que, embora dispendiosa, também Ihe permitiu deixar a imaginação correr livre"29. Ou a teria consumido até a morte? 

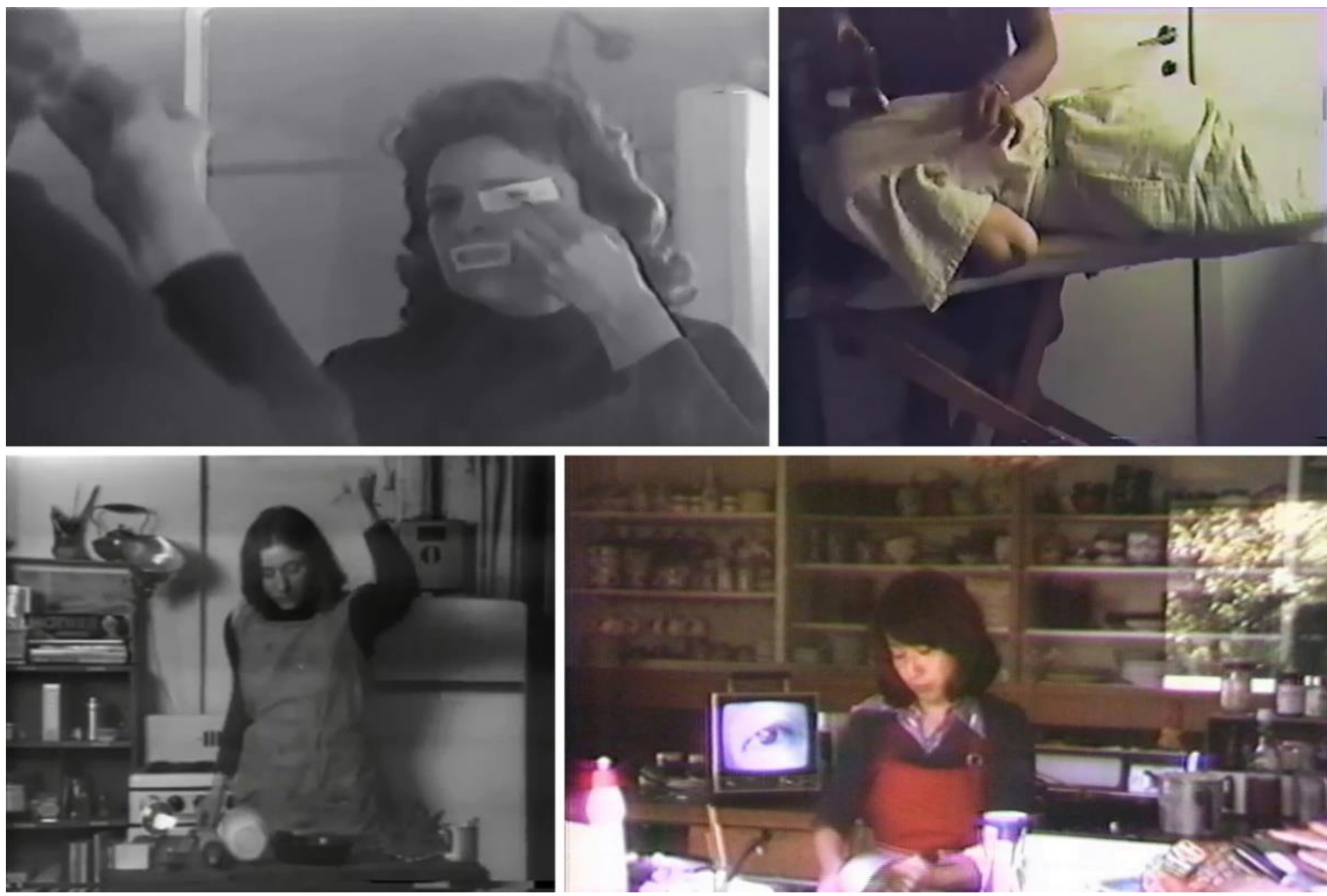

Fig.3. Stills de Preparação 1 (1975) e Tarefa 1 (1982), de Letícia Parente, Semiótica da cozinha (1975), de Martha Rosler, e Outro dia na vida de uma dona-de-casa (1977), de Mako Idemitsu. Fonte: The Sammlung Verbund Collection, Vienna.

Outro conjunto fotográfico é o de Renate Eisenegger (1949, Gelsenkirchen, Alemanha), Arranha-céu $(1974)^{30}$. Nesta obra, a artista maneja um ferro de passar de joelhos no chão em um longo corredor cimentado, com o rosto pintado de branco, destacando "a ausência opressiva de qualquer toque imaginativo característico de tais ambientes residenciais" (Schor, 2005: 37) ${ }^{31}$. Avental de cozinha de dona-de-casa (1975) ${ }^{32}$, de Birgit Jürgenssen (1949-2003, Viena, Áustria), é um díptico, com um registro fotográfico frontal e outro de perfil, remetendo ao enquadramento de registros policiais. Birgit usa um fogão-avental, com a porta do forno aberta por onde sai um fálico pão assado.

Para Schor (2005: 35), Avental de cozinha de dona-de-casa e Semiótica da Cozinha, vídeos produzidos em 1975, têm em comum na abordagem "os significantes da domesticidade, os laços que ligam a mulher ao não remunerado trabalho de reprodução e manutenção"33. Schor (2015) avalia que o caráter monótono e repetitivo dos serviços domésticos condicionara o comportamento de mulheres e este tema é o fio condutor para a leitura de muitas obras da seção Dona-de-casa, mãe, esposa.

A temática do cotidiano e da repetição presentes em Preparação 1 e Tarefa 1 foi também comum em outras produções de videoarte no Brasil dos anos 1970. Gestos cotidianos como "subir e descer 
escadas, assinar o nome, maquiar-se, enfeitar-se, comer, brincar de telefone sem fio - são encenados de modo a produzir uma imagem do corpo" (Parente, 2011: 35). O que se destaca no caso dos vídeos de Letícia é que em geral as ações foram encenadas em ambiente doméstico e boa parte faz referência a tarefas frequentemente realizadas por mulheres, "guardar roupa, passar roupa, costurar, se maquiar" (Ibidem). No próximo tópico, analisamos a seção Reclusão e evasão a partir da presença do vídeo sem título de Sonia Andrade, seguindo com algumas considerações sobre as obras de Letícia Parente.
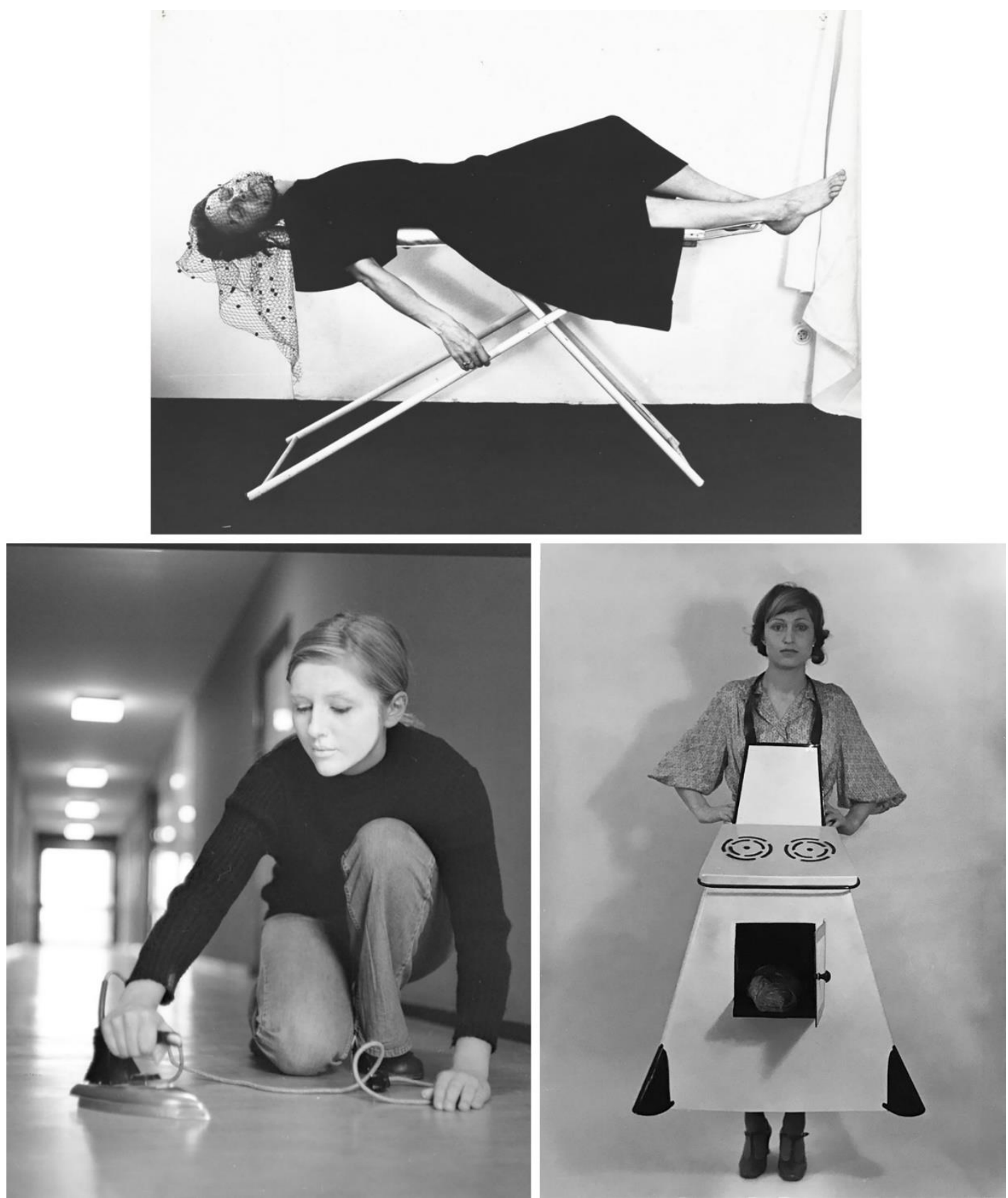

Fig.4. Imagens de Sala de passar roupa (1975), de Karin Mack, Arranha-céus (1974), de Renate Eisenegger, e Avental de cozinha de dona-de-casa (1975), de Birgit Jürgenssen. Fonte: The Sammlung Verbund Collection, Vienna. 


\section{Sonia Andrade, entre fios e fitas na seção Reclusão e evasão}

Há alguns passos de Preparação I e Tarefa I, na seção Reclusão e evasão, está o trabalho sem título (1974-77) ${ }^{34}$ de Sonia [fig. 5]. A ação inicia com a artista passando um barbante pelos furos de ambas orelhas para em seguida ir atravessando o fio pelo rosto inteiro, pressionando bochechas, boca, olhos, nariz, desfigurando sua face pouco a pouco. A imagem, em preto e branco, desaparece em fade out.

O vídeo de Sonia exposto em La Vanguardia Feminista de los años 70 faz parte de um conjunto de 8 vídeos que a artista produziu entre 1974 e 1977 (Costa, 2007; Machado, 2007). Não tivemos acesso aos outros vídeos da série, mas Machado (2007) menciona algumas das ações de Sonia no conjunto no qual a artista, por exemplo, comete pequenas mutilações, corta cabelos do corpo com uma tesoura e confina sua mão em uma mesa com pregos e fios. Machado (2007: 23) interpreta a série como "trabalhos de uma autoviolência latente, meio real e meio fictícia, através dos quais Andrade discorre sobre os têues limites entre lucidez e loucura que caracterizam o ato criador". Já Roberto Moreira Cruz (2007: 10) avalia de aspecto surrealista algumas das ações performadas tanto por Sonia quanto por Letícia, a saber, "bordar com agulha e linha nas solas dos pés, mastigar e engolir folhas de jornal, enrolar na face um fio elétrico". Ainda sobre a série de Sonia Andrade, Trizoli descreve dois vídeos que identifica pelos codinomes Corte e Higiene. Em Corte, Sonia corta cabelos, cílios e sobrancelhas, com uma tesoura de unha de lâmina curta e afiada. Em Higiene, a artista passa fio dental e escova os dentes com gestos intensos e obsessivos. Sobre o conjunto de vídeos, no qual o corpo de Sonia se configura como principal suporte, Trizoli (2018: 75) avalia que existe "uma intensa indiciação de práticas de violência e silenciamento por conta da censura, prisões, torturas, desaparecimentos e mortes durante o regime ditatorial".

As informações dispostas na sessão Reclusão e evasão destacam como recurso da arte feminista dos anos 1970 o uso de jaulas e casulos como metáforas visuais para a opressão patriarcal. Desse modo, a performance de Sonia está justaposta a outras obras feitas com barbantes, fitas e fios, dentre as quais destacamos quatro artistas: Renate Eisenegger, Annegret Soltau, Elaine Shemilt e Lydia Schouten.
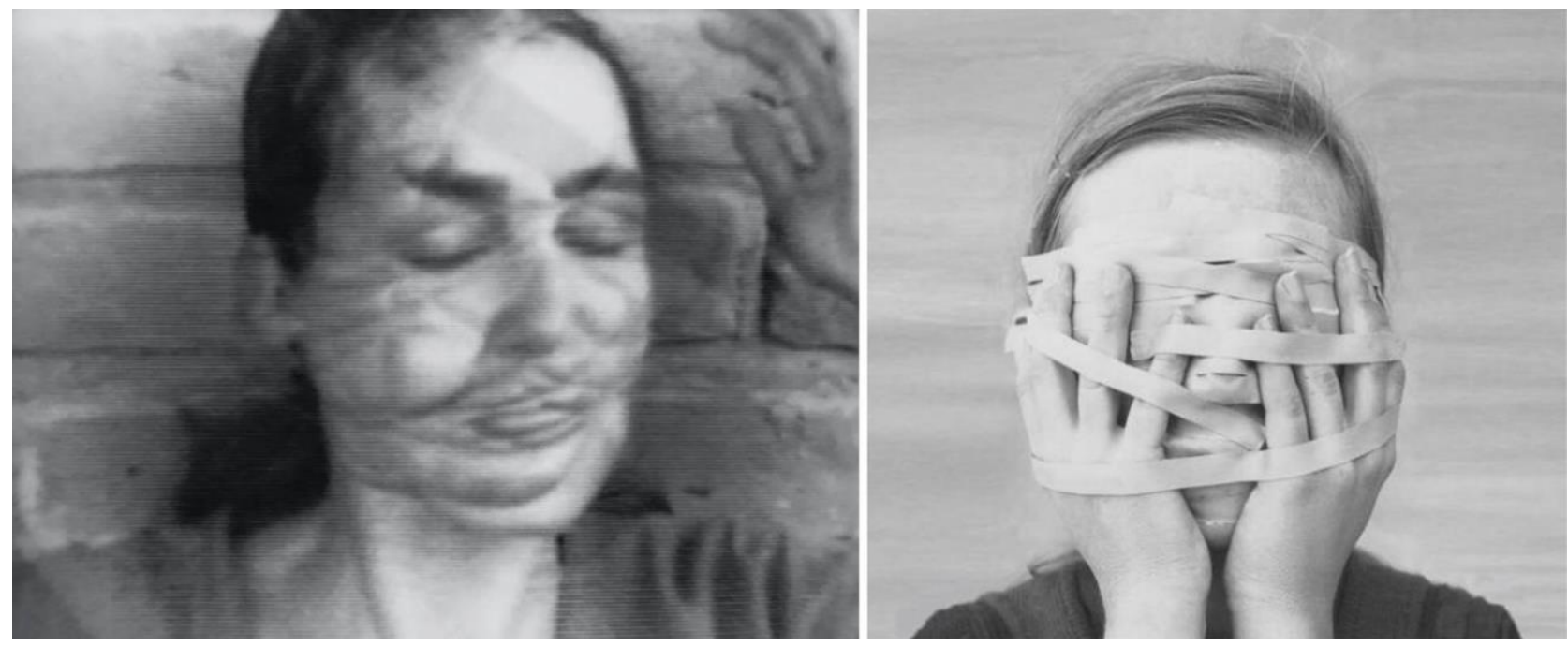

Fig.5. À esquerda, still do vídeo sem título (1974-77), de Sonia Andrade. À direita, a última fotografia do conjunto de 8 imagens de Isolamento (1973), de Renate Eisenegger. Fonte: The Sammlung Verbund Collection, Vienna.

Isolamento (1973) ${ }^{35}$, da alemã Renate Eisenegger [fig. 5], também mencionada no tópico anterior, é uma sequência de oito fotografias, nas quais o rosto da artista vai sendo coberto por pedaços de 
algodão e esparadrapo até prender por completo mãos à cabeça, num quase sufocamento. A Schor (2005), Eisenegger declarou que não há libertação na sua obra, pois considera ainda grande a distância para que o movimento de mulheres possa conquistar o que vem buscando ${ }^{36}$.
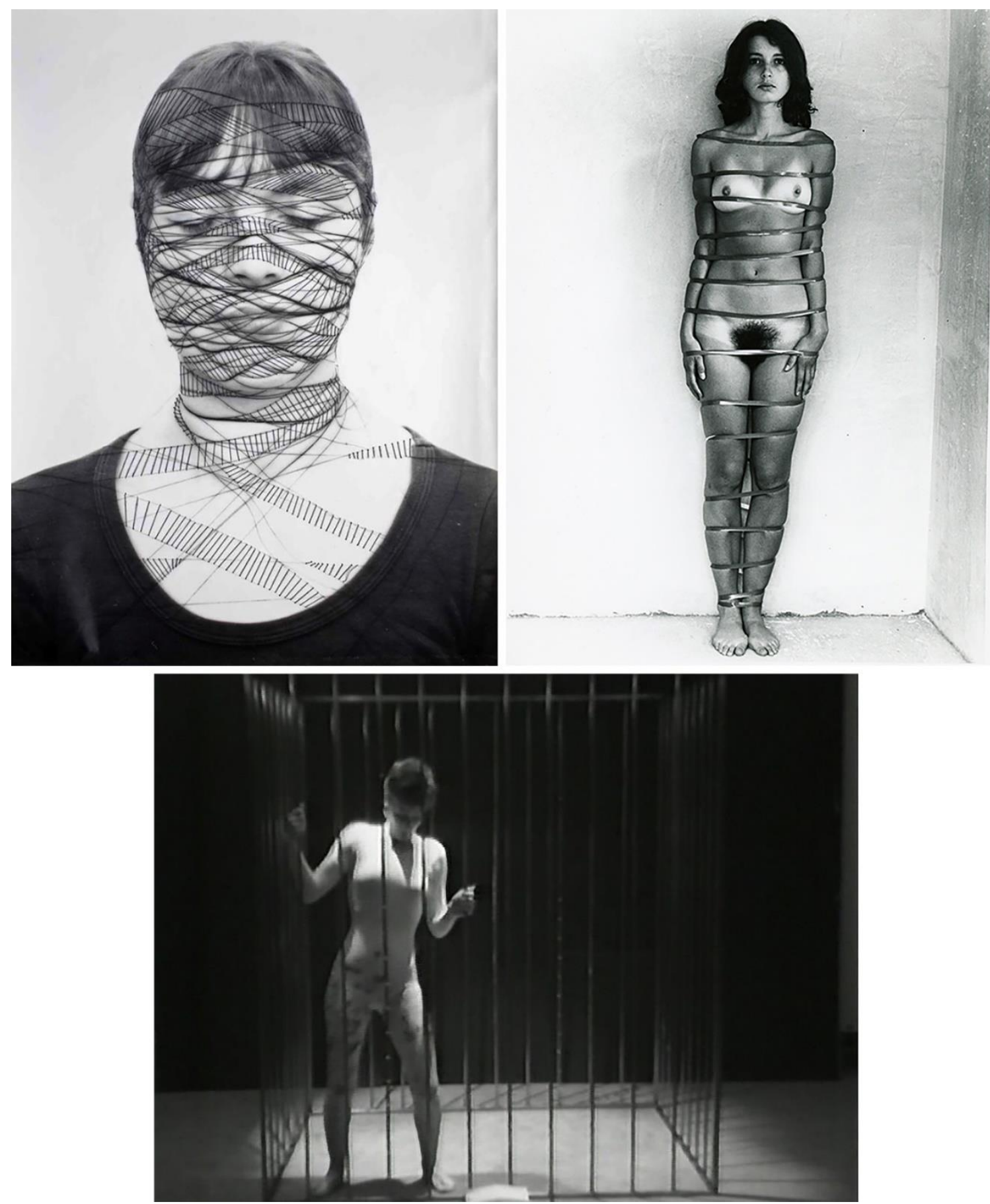

Fig.6. Fotografias de Eu (1973), de Annegret Soltau, e Restrição (1976), de Elaine Shemilt. Imagem do vídeo Gaiola (1978), de Lydia Schouten. 
Eu (1973) ${ }^{37}$, de Annegret Soltau (1946, Lüneburgita, Alemanha) [fig. 6], é uma sequência de 15 fotografias dispostas verticalmente em cinco trípticos, nas quais a artista tem o rosto pouco a pouco coberto por um fino fio preto que acaba cortado por uma tesoura, restando na última imagem apenas um amontoado de linhas emaranhadas, sem a presença de Annegret. Na opinião de Schor (2005), tanto Renate quanto Annegret constroem uma espécie de casulo no entorno da cabeça. No entanto, se em Isolamento o desfecho é de aprisionamento, em Eu há espaço para rompimento e liberdade.

Restrição (1976) ${ }^{38}$, de Elaine Shemilt (1954, Edimburgo, Reino Unido), é outro conjunto de fotografias no qual a artista figura nua com o corpo contornado por fitas [fig. 6]. Sua postura se mantém ereta e no centro da imagem, mas varia em quatro posicionamentos distintos, posando de frente, de costas e laterais. Assim, de modo parecido à Avental de cozinha de dona-de-casa, Restrição remete a fotografias produzidas para o catálogo de instituições de controle e confinamento. A obra foi feita enquanto Elaine era estudante, uma resposta à Reginald Butler (1913-1981), uma das autoridades da Slade School of Art de Londres e então diretor do departamento de escultura, que chegou a afirmar em uma palestra que uma mulher não poderia ser ao mesmo tempo artista e mulher (Schor, 2015).

Dentre as obras audiovisuais de Reclusão e Evasão está Gaiola (1978) ${ }^{39}$, de Lydia Schouten (1948, Leiden, Países Baixos). No vídeo, usando um maiô molhado, a artista se movimenta dentro de uma jaula, esfregando o corpo em lápis aquareláveis pendurados por barbantes que vão colorindo sua pele e sua roupa [fig. 6]. Seus movimentos vão se intensificando, assim como o barulho das vigas de metal sacudindo. Após muitas voltas dentro da estrutura, Lydia se joga no chão, como quem desistiu de escapar, ao menos por hora. Para Schor (2005: 40), Lydia explicou que a metáfora de Gaiola é de "uma mulher que se faz bonita para o mundo, mas não toma parte nele"40.

Todas as artistas que selecionamos para este artigo não apenas conceberam, mas protagonizaram suas obras. No caso da videoarte brasileira, essa era uma característica de muitas das primeiras produções, "a maioria desses vídeos tinha como característica um plano-sequência que registrava a performance ou atitude criativa do artista, realizada com base em um princípio narrativo prosaico" (Cruz, 2007: 9).

No entanto, acerca da leitura feminista proposta pela exposição, enquanto André Parente (2011: 31) avalia no trabalho de Letícia "a disposição para falar da condição da mulher em nossa sociedade", Sonia é enfática ao declarar que não tinha a intenção de tratar essa questão. Em entrevista concedida à Talita Trizoli (2019), a artista explica que no Brasil dos anos 1970 não era possível se "preocupar com o movimento feminista quando tinha uma ditadura barra-pesada. Então nossa batalha, a nossa luta, era contra uma censura pesadíssima..." "41. Sonia também considera não ter sofrido qualquer dificuldade ou interdição aos circuitos artísticos, "pelo fato de ser mulher"42. Além disso, ao justificar sua recusa em participar da exposição Radical Women: Latin American Art43, Sonia manifestou antipatia por projetos expográficos apenas com artistas mulheres, "eu não aguento mais exposição de mulher. Vira gueto, não deixar de ser uma forma de preconceito... eu sou uma artista, eu não tenho sexo. Eu sou uma artista brasileira"44.

As declarações de Sonia apontam para possíveis desacordos na relação de artistas mulheres com projetos curatoriais como La Vanguardia Feminista de los años 70. Concordamos com Trizoli (2019: 59) ao avaliar que "para estas artistas que vivenciaram modificações paradoxais no âmbito político público e privado, a ideia de feminismo não apareceu a partir de uma postura libertária e crítica, mas como uma restrição à sua identidade como artista". Ainda, entendemos que a trajetória de uma obra no tempo e nos espaços pode amplificar as leituras a seu respeito, acrescentando sentidos não previstos na 
concepção, uma vez que o trabalho de curadoria também implica criações discursivas e reinterpretação das obras selecionadas e justapostas.

No entanto, diante do contraste entre a opinião de Sonia sobre exposições de artistas mulheres e 0 discurso curatorial de La Vanguardia Feminista de los años 70, ficam algumas perguntas. Como propor uma leitura feminista a uma artista que não considera a si ou a sua obra feminista? O que faz com que uma artista perceba que as interdições no campo artístico se dão justamente ao participar de projetos expográficos dos quais participam somente mulheres? De que modo a ditadura civil-militar brasileira interferiu na produção de artistas mulheres? Como tratar as contradições e os conflitos envolvidos em um projeto curatorial feminista? Como podem ser expostos os trabalhos de artistas mulheres, feministas ou dissidentes? São perguntas que não esperamos responder nos limites deste recorte, mas que podem mobilizar futuras investigações sobre mulheres, feminismos, artes e exposições.

\section{Algumas considerações sobre barbantes e ferros de passar}

A justaposição dos trabalhos de Letícia e Sonia com obras de outras artistas que, em outros lugares e circunstâncias, usavam táticas e expressões visuais similares tece, por um lado, diálogos entre essas produções e novos sentidos para as obras. Esse, aliás, é um recurso da exposição, indicar no trabalho de mulheres artistas, por vezes geográfica e culturalmente distantes nos anos 1970, elementos visuais e temáticos que se repetem e se aproximam. Por outro lado, há aspectos importantes da conjuntura social sob a qual as obras foram produzidas que sequer são mencionados. No caso de Sonia Andrade e Letícia Parente, não há referência nas legendas da exposição à ditadura civil-militar que o Brasil vivia no momento em que seus vídeos foram produzidos e que exerceu forte influência em muitas produções daquele momento. Caroline Saut Schroeder (2019) discute, por exemplo, os efeitos da política autoritária brasileira nos primeiros anos de ditadura sobre os circuitos artísticos, apontando para a repressão e vigilância constantes, com exposições fechadas, obras censuradas, a descontinuação de eventos, além de restrições ao acesso público. Para Machado (2007: 22), aquela foi a fase mais violenta da ditadura, "com a sociedade amedrontada ou emudecida e as perspectivas de futuro absolutamente sombrias", de modo que as performances não poderiam ser agradáveis ou edificantes, tendendo para uma "auto-imolação transgressiva".

Em La Vanguardia Feminista de los años 70 predomina um espírito de denúncia que precisa ser lido a partir do contexto dos feminismos dos anos 1970. Enquanto que o confinamento e subordinação ao lar foi uma questão apresentada "como uma crise das mulheres, era de fato uma crise somente para um grupo pequeno de mulheres brancas com alto nivel de educação", avalia bell hooks ${ }^{45}$ (2018: 84). Mulheres trabalhadoras, que recebiam baixos salários e também faziam todo o serviço doméstico, possivelmente "teriam enxergado o direito de ficar em casa como 'liberdade' (2018: 84). Portanto, a linha do tempo que ocupa o intervalo espacial entre La Vanguardia Feminista de los años 70 e Coreografías de Género, apesar de limitada ao contexto catalão, indica o desencadeamento de importantes mudanças nas pautas feministas a partir dos anos 1970. Por exemplo, o reconhecimento da interseccionalidade de opressões por gênero, raça, classe social ou deficiências (década de 1990); 0 avanço dos transfeminismos e feminismos decoloniais e racializados (década de 2010) e a mobilização que conseguiu impedir a tentativa de restrição ao direito ao aborto na Espanha (2014).

Reconhecemos que, no caso brasileiro, as restritas condições materiais para a produção de vídeos também subordinaram escolhas estéticas e narrativas como, por exemplo, o registro de planos contínuos, o uso da câmera fixa e limitações no emprego de efeitos sonoros. A partir dos créditos dos 
vídeos também foi possível identificar uma rede de pessoas, eventos e instituições que constituíam os circuitos de produção e circulação dos trabalhos de Sonia, Letícia e outras/os artistas, e que também participaram, em alguma medida, de suas produções.

Apesar das contradições implicadas, entendemos que o formato e a proposta da exposição, assim como seus limites, têm potencialidades. Embora existam leituras sugeridas, as obras são tantas que chegam a parecer cartas embaralhadas que a cada visita à exposição produzem novas relações e descobertas. Se a multiplicidade do conjunto desbota particularidades, a fragmentação também propicia 0 reconhecimento do trabalho de muitas mulheres artistas e da pluralidade de suas produções. São obras por vezes pouco conhecidas e que a partir das exposições passam a circular em catálogos, notícias de jornal, postagens de redes sociais e investigações acadêmicas.

Incluir Letícia Parente e Sonia Andrade em La Vanguardia Feminista de los años 70 suscita novas leituras às suas obras, a partir de diálogos com outras produções e outras artistas, de outros países. Consideramos, portanto, que sua presença resulta em contradições e deslocamentos que precisam ser debatidos, mas, sobretudo, possibilita que estas artistas ocupem lugar em uma exposição e uma coleção que constituem espaços oportunos e potentes para discussões sobre artes, mulheres e feminismos.

\section{Referências}

CENTRO DE CULTURA CONTEMPORÂNEA DE BARCELONA (CCCB). Disponível em: < https://www.cccb.org/es/exposiciones/ficha/fem inismos/231713>. Acesso em 15 dez. 2019.

COSTA, C. T. da. Videoarte no MAC. In: MACHADO, Arlindo (org). Made in Brasil. Três Décadas do Vídeo Brasileiro. São Paulo: lluminuras, Itaú Cultural, 2007.

CRUZ, R. M. S. Cortes e recortes eletrônicos. In: MACHADO, Arlindo (org). Made in Brasil. Três Décadas do Vídeo Brasileiro. São Paulo: Iluminuras, Itaú Cultural, 2007.

hooks, b. O feminismo é para todo mundo: políticas arrebatadoras. Rio de Janeiro: Rosa dos tempos, 2018 [recurso digital].

MACHADO, A. As linhas de força do vídeo Brasileiro. In: MACHADO, A. (org). Made in Brasil. Três Décadas do Vídeo Brasileiro. São Paulo: lluminuras, Itaú Cultural, 2007.

OLIVEIRA, M. M. de. Letícia Parente. The body and the opus as a witness of time. In: SCHOR, Gabriele. Feminist Avant-Garde. Art of the 1970s. The Sammlung Verbund Collection,
Vienna. Munich, London, New York: Prestel, 2015.

PARENTE, A. Alô, é a Letícia? In: PARENTE, A.; MACIEL, K. (orgs.) Leticia Parente. Rio de Janeiro: +2 Editora, 2011.

SAMMLUNG VERBUND, 2020. Disponível em: $<$ <ttps://www.verbund.com/en-at/aboutverbund/responsibility/art-collection>. Acesso em 03 jan. 2020.

SCHROEDER, C. S. As artes visuais sob vigilância: censura e repressão nos anos de ditadura. MODOS. Revista de história da arte. v. 3, n. 3, p. 45-59, 2019.

SCHOR, G. Feminist Avant-Garde. Art of the 1970s. The Sammlung Verbund Collection, Vienna. Munich, London, New York: Prestel, 2015.

TRIZOLI, T. Atravessamentos feministas: um panorama de mulheres artistas no Brasil dos anos 60/70. Tese (Doutorado). Faculdade de Educação, Universidade de São Paulo: São Paulo, 2018.

\section{Notas}

\footnotetext{
* O presente trabalho foi realizado com apoio da Coordenação de Aperfeiçoamento de Pessoal de Nível Superior - Brasil (CAPES) Código de Financiamento 001.
} 
** Na Universidade Tecnológica Federal do Paraná (UTFPR) é professora no Departamento Acadêmico de Desenho Industrial (DADIN) e doutoranda no Programa de Pós-Graduação em Tecnologia e Sociedade (PPGTE). Atualmente é pesquisadora visitante na Universidade de Barcelona (UB), com bolsa pelo Programa de Doutorado-Sanduíche no Exterior (PDSE/CAPES). E-mail: <oianafanca@gmail.com>. ORCID: <https://orcid.org/0000-0002-8174-1446>.

${ }^{* * *}$ Mestre pelo PPGTE/UTFPR (2003), Doutor pelo PPGICH/UFSC (2008) e Pós-doutorado no PPGAS/UFRGS (2012-2013). Em 2007 realizou estágio de doutoramento no México - D.F., com bolsa da CAPES, no Posgrado en Ciéncias Antropológicas da Universidad Autónoma Metropolitana - unidad Iztapalapa. É professor no Departamento de Design da UFPR, do Programa de Pós-Graduação em Design na mesma instituição e professor convidado do Programa de Pós-Graduação em Tecnologia da UTFPR. E-mail: <olive.ronaldo@gmail.com>. ORCID: < https://orcid.org/0000-0003-1894-1944>.

1 Optamos por indicar entre parênteses o ano e a cidade de nascimento, e também de morte da artista, quando for o caso.

2 Além de Regina Vater, Sonia Andrade e Letícia Parente, o site da coleção Sammlung Verbund: The Verbund Art Collection informa que também fazem parte do acervo Georgia Creimer (1964, São Paulo), Roberta Lima (1974, Manaus) e Ernesto Neto (1964, Rio de Janeiro).

3 Pilar Aymerich (1943, Barcelona, Espanha); Eugènia Balcells (1943, Barcelona, Espanha); Mari Chordà (1942, Amposta, Espanha); Marisa González (1945, Bilbao, Espanha); Eulàlia Grau (1946, Terrassa, Espanha); Fina Miralles (1950, Sabadel, Espanha); Àngels Ribé (1943, Barcelona, Espanha) e Dorothée Selz (1946, Paris, França).

${ }^{4}$ Gabriele Schor é crítica, colecionadora e curadora de arte (1961, Viena, Áustria).

${ }^{5}$ A Verbund é uma empresa de eletricidade localizada na Áustria. A Sammlung Verbund: The Verbund Art Collection, Vienna é uma coleção de arte fundada em 2004 e coordenada por Gabriele Schor, parte das iniciativas de responsabilidade social da empresa.

${ }^{6}$ Marta Segarra é pesquisadora e professora de Literatura Francesa e Estudos de Gênero na Universidade de Barcelona (1963, Barcelona).

${ }^{7}$ Discriminação baseada na espécie. 0 termo é utilizado para questionar a atribuição de diferentes direitos e valores aos animais por estes serem considerados inferiores.

${ }^{8} \mathrm{~A}$ Catalunha é uma comunidade autônoma da Espanha composta por 4 províncias (Barcelona, Girona, Lérida e Tarragona), localizada na extremidade leste da Península Ibérica.

${ }^{9}$ Marika Vila é historiadora e ilustradora (1949, Barcelona).

10 Tradução livre do espanhol: Ama de casa, madre, esposa; Reclusión y evasión; Los dictados de la belleza; La sexualidad femenina e Juegos de rol. No site da coleção, a versão em inglês dos títulos das sessões pode matizar os seus sentidos: The Reduction to Mother, Housewife, and Wife; Locked-up, Break-out; The Normativity of Beauty; Female Sexuality versus Objectification; Alter Ego: Masquerade, Parody, and Role Plays (Sammlung Verbund, 2019).

${ }^{11}$ Há uma divergência entre informações do site do CCCB e do site da coleção, que informa serem 350 obras expostas em Barcelona (Sammlung Verbund, 2020).

12 Filmes da playlist Feminsmes! do Arxiu Xcèntric: Schmeerguntz (Gunvor Nelson e Dorothy Wiley, 1965); Fuses (Carolee Schneemann, 1966); Saute ma ville (Chantal Akerman, 1968); Réponse de femmes: Notre corps, notre sexe (Agnès Varda, 1975); Mann \& Frau \& Animal (Valie Export, 1973); All can become a rose (Linda Christanell, 1992); Kantate (Maria Lassnig e Hubert Sielecki, 1992); Removed (Naomi Uman, 1999).

${ }^{13}$ Visitas comentadas (com guia em língua de sinais; com guia para pessoas com cegueira ou baixa visão): Feminismes! em família; visita guiada por Marta Segarra. Visitas comentadas temáticas: Eloy Fernández Porta, "El género: norma, anomalía y progreso"; Bel Olid, "¿Una para todas? Todas para todo"; Najat El Hachmi, "Feminismo: ¿legado universal o dominación colonial?"; Miquel Missé, "Trans Outsiders? Buscarse en el espejo del arte feminista"; Tania Adam, "Nací en un matriarcado y me han educado par a ser una mujer como es debido".

${ }^{14}$ Ciclo de eventos, conferências e debates: "Las muertes chiquitas", Proyección del documental y conversación con Mireia Sallarès y Marta Segarra; "Quimera Rosa", acción participativa de bioarte; "La cara B del turismo en Barcelona", acción con el colectivo Las Kellys; "Irreductibles", Performances feministas; "Indòmites", una obra de Xamfrà y Las Anónimas; "'Así bailan las putas', en el Escenari Joan Brossa", coloquio postfunción con la compañía; "Una mañana con Marta Segarra, ¿Qué es ser feminista hoy?"; "Cosa/Cos. La bellesa subvertida", una creación de Les Impuxibles y Judit Colomer Mascaró; Conversación con Siri Hustvedt; "Alzar las manos, estas, sucias", recital de poetas de los setenta y de ahora; "Silencio y emancipación", conferencia de Carolin Emcke; "FEM!", creadoras feministas de hoy; "Acciones de resistencia" en el Escenari Joan Brossa; "Un feminismo en transformación", conferencia de Mari Luz Esteban; Conversación con Jeanette Winterson; "GRRRLS!!! Manifestos feministes", una obra de Carlota Subirós; "La ira", conferencia de Chantal Maillard"; "Igualdad y libertad", conversación entre Fina Birulés y Marta Segarra.

${ }^{15} \mathrm{Na}$ ordem do percurso expográfico estão as seguintes obras audiovisuais (apresentamos título no idioma original e ano da obra; nome da artista; ano, cidade e país de nascimento e falecimento, quando for o caso): Semiotics of the kitchen, 1975, de Martha Rosler (1943, Nova lorque, EUA); Erinnerung, 1979-1980, de Annegret Soltau (1946, Lüneburgita, Alemanha); Preparação 1, 1975 e Tarefa 1, 1982, de Letícia Parente (1930, Salvador de Bahia, 1991, Rio de Janeiro, Brasil); Another Day of a Housewife, 1977, de Mako Idemitsu (1940, Tóquio, Japão); Sem título, 1974-1977, de Sonia Andrade (1935, Rio de Janeiro, Brasil); Elnwicklung mit Julia, 1972, de Ulrike Rosenbach (1943, Bad Salzdetfurth, Alemanha); Kool, 1978, de Lydia Schouten (1948, Leiden, Países Baixos); Free, White and 21, 1980, de Howardena Pindell (1943, Filadélfia, EUA); Burial Pyramid, Yagul, Mexico, 1984, de Ana Mendieta (1948, Havana, Cuba, 1985, Nova lorque, EUA); Quadrille, 1975-2013, de Rose English (1950, Hereford, Reino Unido); Fingerfächer, 1975/1982, de Linda Christanell (1939, Viena, Áustria); Female Sensibility, 1973, de Lynda Benglis (1941, Lake Charles, EUA); Through the Large Glass, 1976, de Hannah Wilke (1940, Nova lorque, 1993, Houston, EUA); Sexobject, 1978, de Lydia Schouten (1955, Leiden, Países Baixos); In Mourining and In Rage, 1977-1978, de Leslie Labowitz (1946, Uniontown, EUA) e Suzanne Lacy (1945, Wasco, EUA); La femme sans tête ou la danse du ventre, 1974, de Nil Yalter (1938, El Cairo, Egito); Tapp und Tastkino, 1968, de VALIEValie EXPORT (1940, Linz, Áustria); Consumer Art, 1972-1975, de Natalia LL (1937, Zywiec, Polônia); Glauben Sie nicht, dass ich eine Amazone bin, 1975-1976, de Ulrike Rosenbach (1943, Bad Salzdetfurth, Alemanha); The king, 1972, de Eleanor Antin (1935, Nova lorque, EUA); 
Technology/Transformation. Wonder Woman, 1978-79, de Dara Birnbaum (1946, Nova lorque, EUA); Doll Clothes, 1975-2006, de Cindy Sherman (1954, Glen Ridge, EUA); Going through languages, 1981, de Eugènia Balcells (1943, Barcelona, Espanha).

${ }^{16}$ Registro em Digibeta PAL, digitalizado, preto e branco, sonoro, 3'29".

${ }_{17}^{17}$ Registro Digibeta PAL, digitalizado, colorido, sonoro, 1'56".

18 Cámara Argentina de la Industria Cinematográfica.

19 Jom Tob Azulay, produtor e diretor de fotografia (1941, Rio de Janeiro, Brasil).

${ }^{20}$ Anna Bella Geiger, escultora, pintora, artista intermídia (1933, Rio de Janeiro); Ivens Olinto Machado, escultor, gravador e pintor (1942, Florianópolis, 2015, Rio de Janeiro); Ângelo de Aquino, pintor e desenhista (1945, Belo Horizonte - 2007, Rio de Janeiro) e Fernando Cocchiarale, curador e crítico de arte (1951, Rio de Janeiro).

21 Walter Zanini foi encarregado de convidar artistas a participarem e "convidou Regina Silveira, Julio Plaza, Donato Ferrari e Gabriel Borba, que, em São Paulo, não conseguira equipamentos para os seus projetos" (Costa, 2007: 73).

22 Suzanne Delehanty, curadora de arte (1944, Southbridge, EUA).

${ }^{23}$ Walter Zanini, crítico e curador de arte (1925, São Paulo, 2013, São Paulo).

$24 \mathrm{O}$ objetivo do setor era trabalhar em três frentes de produção: 1. Estudo histórico do vídeo; 2. Realização de exposições dedicadas ao vídeo e 3. Espaço para pesquisa de artistas em colaboração com o museu (Costa, 2007).

${ }^{25}$ Anna Bella Geiger, Fernando Cocchiarale, Ivens Machado, Letícia Parente, Miriam Danowski, Paulo Herkenhoff e Sonia Andrade.

${ }^{26}$ Tradução livre do original em inglês: Semiotics of the kitchen. Digibeta PAL, digitalizado, preto e branco, sonoro, 6'09".

${ }^{27}$ Tradução livre do inglês: Another Day of a Housewife. Registro em vídeo NTSC, colorido, sonoro, 9'50".

28 Tradução livre do original em alemão: Bügeltraum. Em catalão, a obra foi apresentada como Somni de planxar. Fotografia preto e branca.

29 Tradução livre do original em inglês: Interpreted ironing as a contemplative practice that, while time consuming, also allowed her to let her imagination run free (Schor, 2005: 37).

30 Tradução livre do original em alemão: Hochhaus. Em catalão a obra foi apresentada como Bloc de pisos. Fotografias em preto e branco montadas em madeira.

${ }^{31}$ Tradução livre do original em inglês: "to highlight the opressive absence of the slightest imaginative touch caractheristic of such residential settings" (Schor, 2005: 37).

32 Tradução livre do original em alemão: Hausfrauen-Küchenschürze. Em catalão a obra foi apresentada como Davantal de cuins de mestressa de casa. Fotografia preto e branca.

${ }^{33}$ Tradução livre do original em inglês: "both artists adresses the signifiers of domesticity, the ties that bind woman to unpaid reproductive and maintenance labor" (Schor, 2005: 35).

${ }^{34}$ Registro com Portapack, digitalizado, preto e branco, sonoro, 2'42".

35 Título original. Em catalão a obra foi apresentada como Aïllament. Fotografias em preto e branco montadas em madeira.

${ }^{36}$ Entrevista de Renate Eisenegger concedida a Gabriele Schor em 2014.

${ }^{37}$ Tradução livre do original em alemão: Selbst. Em catalão a obra foi apresentada como Jo. Fotografias preto e branca. Papel fotográfico, fio preto, montadas em papelão.

${ }^{38}$ Tradução livre do original em inglês: Constraint. Em catalão, a obra foi apresentada como Limitació. Fotografias em preto e branco.

39 Tradução livre do original em holandês: Kooi. Em catalão, a obra foi apresentada como Gàbia. Vídeo, sonoro, preto e branco, 17'43".

40 Tradução livre do original em inglês: "a woman is making herself beautiful for the outside world, but doesn't take part in it" (SCHOR, 2005: 40). Lydia Schouten em comunicação por e-mail com Gabriele Schor.

${ }^{41}$ Entrevista com Sonia Andrade concedida a Talita Trizoli em 17 out. 2017 (Trizoli, 2019: 59).

42 Entrevista com Sonia Andrade concedida a Talita Trizoli em 17 out. 2017 (Trizoli, 2019: 59).

${ }^{43}$ Exposição e arquivo digital com mais de 120 artistas e coletivos ativos entre 1965 e 1980. Exposições do projeto já ocorreram no Hammer Museum de Los Angeles, no Brooklyn Museum e na Pinacoteca de São Paulo.

44 Entrevista com Sonia Andrade concedida a Talita Trizoli em 17 nov. 2017 (Trizoli, 2019: 74).

45 bell hooks escreve seu nome em letras minúsculas.

Artigo recebido em janeiro de 2020. Aprovado em abril de 2020. 